\title{
Produção de mudas de ipê roxo em substratos a base de caule decomposto de babaçu
}

\author{
Myllenna da Silva Santana ${ }^{1}$, Ana Paula de Sousa Almeida ${ }^{1}$, Samuel Ferreira Pontes ${ }^{1}$, Carlos Alberto Araújo \\ Costa $^{1}$, Analya Roberta Fernandes Oliveira ${ }^{2}$, Raissa Rachel Salustriano da Silva-Matos ${ }^{1}$
}

RESUMO: Informações técnicas relacionadas ao uso de substratos alternativos podem conduzir a produção de mudas com qualidade e com custo reduzido, permitindo que a cultura atinja seu máximo potencial genético. Diante do exposto, objetivou-se avaliar o caule decomposto de babaçu no desenvolvimento de mudas de ipê-roxo. Foi adotado um delineamento inteiramente casualizado, com seis tratamentos, nos quais os substratos foram compostos a base de caule decomposto de babaçu (CDB), nas seguintes proporções: T1- 100\% de solo; T2-20\% de CDB + 80\% de solo; T3-40\% de $\mathrm{CDB}+60 \%$ de solo; $\mathrm{T} 4-60 \%$ de $\mathrm{CDB}+40 \%$ de solo; $\mathrm{T} 5-80 \%$ de $\mathrm{CDB}+20 \%$ de solo e T6- $100 \%$ de CDB, com quatro repetições, de cinco mudas cada. Foram analisadas as variáveis: número de folhas, altura da planta, volume radicular, massa fresca da parte aérea, massa fresca do sistema radicular, massa seca da parte aérea e massa seca do sistema radicular. Foi realizada análise de variância pelo Teste $\mathrm{F}$ e teste de média Tukey pelo software Assistat ${ }^{\circledR}$. Não foi registrada diferença significativa apenas para as variáveis diâmetro e comprimento do caule. O substrato com $60 \%$ de caule decomposto de babaçu (Attalea speciosa Mart.) apresenta melhores resultados na produção de mudas de ipêroxo.

Palavras-chave: Attalea speciosa, nutrição, substratos regionais, Tabebuia impetiginosa.

\section{Production of purple ipê seedlings on substrates based on the decomposed stem of babassu}

\begin{abstract}
Technical information related to the use of alternative substrates can lead to the production of quality seedlings at a reduced cost, allowing the crop to reach its maximum genetic potential. In view of the above, the objective was to evaluate the decomposed stem of babassu in the development of ipê-roxo seedlings. A completely randomized design was used, with six treatments, in which the substrates were composed of a babaçu decomposition stem (CBD), in the following proportions: T1- $100 \%$ of soil; T2-20\% of CBD $+80 \%$ of soil; $\mathrm{T} 3-40 \%$ of CBD $+60 \%$ of soil; T4-60\% of CBD $+40 \%$ of soil; $\mathrm{T} 5-80 \%$ of $\mathrm{CBD}+20 \%$ of soil and $\mathrm{T} 6-100 \%$ of $\mathrm{CBD}$, with four replicates, of five seedlings each. The following variables were analyzed: leaf number, plant height, root volume, fresh shoot mass, fresh root mass, dry shoot mass and dry mass of the root system. Variance analysis was performed by the F-Test and Tukeymean test by the Assistat ${ }^{\circledR}$ software. No significant difference was registered only for the variables stem diameter and stem length. The substrate with $60 \%$ of babaçu decomposed stem (Attalea speciosa Mart.) Presents better results in the production of ipê-purple seedlings.
\end{abstract}

Keywords: Attalea speciosa, nutrition, regional substrates, Tabebuia impetiginosa.

\section{INTRODUÇÃO}

O ipê-roxo (Tabebuia impetiginosa (Mart.) Standl.) pertence à família Bignoniaceae que ocorrem em várias regiões do Brasil. É de grande valor madeireiro, medicinal e ornamental, e apresenta ampla utilização na arborização urbana e na recomposição vegetal de áreas degradadas (BORBA FILHO et al., 2009).

A sua madeira é pesada, apresentando dureza ao corte, além de ser resistente a organismos que se alimentam de madeira (xilófagos). Além disso, é uma espécie utilizada para ornamentação, muito indicada para o paisagismo em geral. Por apresentar uma beleza exuberante, o ipê-roxo tem sido muito utilizado em projetos de arborização urbana e paisagismo, bem como sua madeira que é de ótima qualidade, podendo ser destinada a vários fins de utilização (ALVES, FREIRE, 2017).

Esta espécie vem sendo empregada na medicina popular para o tratamento contra alguns tipos de câncer, lúpus, doença de Parkinson, psoríase e alergia, além de apresentar atividades hipoglicemiante, depurativo, bactericida, antifúngico, diurético e adstringente e tem sido utilizada para reconstituição de Reserva Legal e

Recebido em 29/11/2018; Aceito para publicação em 11/01/2019

${ }^{1}$ Universidade Federal do Maranhão

2 Universidade Federal deo Ceará

*E-mail: raissasalustriano@yahoo.com.br 
programas de recuperação de áreas degradadas (OLIVEIRA et al., 2015).

É fundamental que as mudas sejam de qualidade antes de serem destinadas ao plantio, então, é necessário a utilização de substratos que proporcionem boas condições de desenvolvimento para a produção das mesmas.

Segundo Oliveira Neto et al. (2018a) o substrato é muito importante para a obtenção de mudas saudáveis e vigorosas. Geralmente sua escolha depende do custo de produção e disponibilidade regional. Oliveira Neto et al. (2018a) dizem ainda que o substrato deve ter uma combinação de características físicas e químicas que promovam a retenção de umidade e a disponibilidade de água e nutrientes, de modo a atender às necessidades das plantas. Dentre os materiais que apresentam potencial para composição do substrato, destaca-se o caule decomposto da palmeira de babaçu (Attalea speciosa Mart.), originário das regiões norte e nordeste do Brasil.

No leste da Amazônia e na região da floresta de Cocais localizada no estado do Maranhão, Brasil, existe a maior aglomeração e incidência natural de palmeiras de babaçu no mundo. Essa palmeira é uma das principais fontes de exploração de agroextrativistas, cujo principal produto é o óleo de amêndoa de sua fruta. Atualmente, o caule da palmeira de babaçu após o processo de decomposição tem sido utilizado como substrato alternativo pelos produtores rurais para a produção de mudas (CRUZ et al., 2018).

$\mathrm{Na}$ região pré-amazonica as comunidades tradicionais e agricultores familiares usam o caule da palmeira de babaçu como substrato alternativo. Um dos fatores que colaboram para essa vasta utilização está relacionada à disponibilidade regional, estimase florestas de babaçuais espontâneas com média de 1111 a 4000 plantas.ha ${ }^{-1}$, sendo o fruto dessa palmácea, o côco babaçu, um produto com vasta utilização como na alimentação animal e humana, fonte de biomassa, indústria farmacêutica e artesanato (QUEIROGA et al., 2015).

Nessa perspectiva, informações técnicas relacionadas ao uso de substratos contendo o caule decomposto de babaçu podem possibilitar o uso mais racional, e conduzir a produção de mudas de maior qualidade, com custo reduzido, permitindo que a cultura atinja seu máximo potencial genético. Considerando que a caracterização física de substratos é importante para o conhecimento e a padronização dos insumos e, principalmente, para que os agricultores possam decidir de forma consciente por sua aquisição e uso, as indústrias possam melhorar a qualidade (OLIVEIRA et al., 2018).
Assim, objetivou-se avaliar diferentes proporções de substrato a base de caule decomposto de babaçu na germinação e a biometria de mudas de Ipê roxo.

\section{MATERIAL E MÉTODOS}

O experimento com mudas de ipê-roxo (Tabebuia impetiginosa) foi realizado entre os meses de março a maio de 2018, produzido com substratos a base de caule decomposto de babaçu, conduzido em casa de vegetação no Centro de Ciências agrárias e Ambientais (CCAA) da Universidade Federal do Maranhão (UFMA), localizado no município de Chapadinha-MA, situado a $03^{\circ} 44^{\prime} 30^{\prime \prime}$ de latitude Sul, 4321'37', de longitude Oeste e altitude média de $107 \mathrm{~m}$. O município de Chapadinha pertence à região do cerrado maranhense com clima quente e úmido segundo a classificação de Köppen (Aw), com temperatura média anual superior a $27{ }^{\circ} \mathrm{C}$ e precipitação pluvial média anual de $1835 \mathrm{~mm}$; a umidade relativa do ar anual fica entre 73 e $79 \%$. As altitudes variam bastante, possui relevo ondulado a suave ondulado (PASSOS et al, 2016).

Foi adotado um delineamento inteiramente casualizado com seis tratamentos, nos quais os substratos foram compostos a base de caule decomposto de babaçu (CDB), nas seguintes proporções: T1- $100 \%$ de solo; T2-20\% de CDB + $80 \%$ de solo; $\mathrm{T} 3-40 \%$ de CDB $+60 \%$ de solo; $\mathrm{T} 4-$ $60 \%$ de $\mathrm{CDB}+40 \%$ de solo; $\mathrm{T} 5-80 \%$ de $\mathrm{CDB}+$ $20 \%$ de solo e T6- $100 \%$ de CDB dispostos em quatro repetições, compostas de 5 mudas cada. Foram utilizados sacos de polietileno, preenchidos com os substratos formulados. As sementes utilizadas foram coletadas em árvore matriz sendo semeadas uma em cada saco a $1 \mathrm{~cm}$ de profundidade, e a irrigação foi realizada duas vezes ao dia, com o uso de regador manual. $\mathrm{O}$ experimento foi avaliado aos 60 dias após o início sendo avaliadas 120 mudas.

Nas Tabelas 1 e 2 pode-se verificar a caracterização química e física dos substratos. E no solo que compõem os substratos com $\mathrm{CDB}$, foi realizada análise granulométrica: $384 \mathrm{~g}$ areia grossa/kg; $336 \mathrm{~g}$ areia fina/kg; $112 \mathrm{~g}$ de silte $/ \mathrm{kg} ; 168$ $\mathrm{g}$ de argila total $/ \mathrm{kg} ; 38 \mathrm{~g}$ de argila natural $/ \mathrm{kg}$; classificação textural Franco arenosa; e grau de floculação de $77 \mathrm{~g} / 100 \mathrm{~g}$. 
Tabela 1. Valores de $\mathrm{pH}$, condutividade elétrica $(\mathrm{CE})$ e teores totais de nitrogênio $(\mathrm{N})$, fósforo $(\mathrm{P})$, potássio $(\mathrm{K})$, cálcio $(\mathrm{Ca})$, magnésio (Mg) e enxofre ( $\mathrm{S}$ ), do substrato comercial e dos substratos a base de caule decomposto de babaçu (CDB).

\begin{tabular}{ccccccccc}
\hline Substratos & $\mathrm{pH}$ & $\begin{array}{c}\mathrm{CE} \\
\mathrm{dS} \mathrm{m}\end{array}$ & $\begin{array}{c}\mathrm{N} \\
\mathrm{g} \mathrm{kg}^{-1}\end{array}$ & $\begin{array}{c}\mathrm{P} \\
\mathrm{mg} \mathrm{kg}^{-1}\end{array}$ & & $\mathrm{~K}$ & $\begin{array}{c}\mathrm{Ca} \\
\mathrm{cmolc} \mathrm{kg}^{-1}\end{array}$ & $\mathrm{~S}$ \\
\hline $\mathrm{T} 1$ & 4,92 & 2,78 & 3,08 & 553 & 2,89 & 22,50 & 3,40 & 29,4 \\
$\mathrm{~T} 2$ & 4,88 & 0,61 & 1,23 & 14 & 0,67 & 1,60 & 1,00 & 3,8 \\
T3 & 5,11 & 1,36 & 1,46 & 13 & 1,82 & 3,20 & 1,70 & 7,6 \\
T4 & 4,83 & 1,79 & 2,02 & 13 & 2,35 & 4,40 & 2,80 & 10,8 \\
T5 & 5,16 & 3,00 & 3,47 & 27 & 6,17 & 10,90 & 4,60 & 24,6 \\
T6 & 5,32 & 4,34 & 5,88 & 33 & 3,63 & 20,60 & 15,20 & 41,5
\end{tabular}

$\mathrm{T} 1=\overline{100 \% \text { de solo; } \mathrm{T} 2=20 \% \text { de } \mathrm{CDB}+80 \% \text { de Solo; } \mathrm{T} 3=40 \% \text { de } \mathrm{CDB}+60 \% \text { de Solo; } \mathrm{T} 4=60 \% \text { de } \mathrm{CDB}+\text { de } 40 \% \text { Solo; }}$ T5= $80 \%$ de $\mathrm{CDB}+20 \%$ de Solo; e T6=100\% de CDB.

Tabela 2. Densidade global (DG), densidade de partícula (DP) e porosidade (P) do substrato comercial e dos substratos a base de caule decomposto de babaçu (CDB).

\begin{tabular}{cccc}
\hline Substratos & \multicolumn{2}{c}{ Densidade $\left(\mathrm{g} / \mathrm{cm}^{3}\right)$} & Porosidade $(\%)$ \\
& DG & DP & \\
\hline T1 & 0,56 & 0,85 & 34,43 \\
T2 & 1,28 & 2,64 & $51,53 \mathrm{~b}$ \\
T3 & 1,18 & 2,57 & 54,01 \\
T4 & 0,98 & 2,24 & 56,22 \\
T5 & 0,73 & 1,88 & 60,91 \\
T6 & 0,33 & 0,97 & 65,95
\end{tabular}

$\mathrm{T} 1=\overline{100 \% \text { de solo; } \mathrm{T} 2=20 \% \text { de } \mathrm{CDB}+80 \% \text { de Solo; } \mathrm{T} 3=40 \% \text { de } \mathrm{CDB}+60 \% \text { de Solo; } \mathrm{T} 4=60 \% \text { de } \mathrm{CDB}+\text { de } 40 \% \text { Solo; }} \mathrm{T}=$ $80 \%$ de $\mathrm{CDB}+20 \%$ de Solo; e T6= $100 \%$ de CDB.

Aos 60 dias após a semeadura foram avaliadas as seguintes variáveis: i) Altura da planta (AP): determinada a partir do nível do solo ao ápice da planta com auxílio de régua milimétrica; ii) diâmetro do caule (DC): obtido com paquímetro digital (Digimess ${ }^{\circledR}$ ); iii) número de folhas (NF): determinada pela contagem de folhas em cada plântula; iv) volume radicular (VR): determinado em proveta graduada, segundo metodologia descrita por Basso (1999); v) comprimento radicular (CR): medido com auxílio de uma régua graduada em milímetros; vi) massa fresca da parte aérea (MFPA), vii) massa fresca radicular (MFR), viii) massa seca da parte aérea (MSPA) e ix) massa seca do sistema radicular (MSSR) - (g) obtidos pelo método da secagem em estufa com circulação forçada de ar à temperatura de $65^{\circ} \mathrm{C}$ até atingir massa constante.

Os dados foram submetidos à análise de variância pelo teste " $F$ ", para diagnóstico de efeito significativo, e os tratamentos comparados entre si pelo teste Tukey a $5 \%$ de probabilidade, através do programa computacional Assistat ${ }^{\circledR}$ (SILVA, AZEVEDO, 2016).

\section{RESULTADOS E DISCUSSÃO}

Os substratos com crescentes proporções de caule decomposto de babaçu (CDB) na produção de mudas de Ipê roxo proporcionaram efeito significativo para as variáveis número de folhas, altura da planta, volume radicular (Tabela 3), massa fresca da parte aérea, massa fresca do sistema radicular, massa seca da parte aérea e massa seca do sistema radicular (Tabela 3) com nível de significância de 1 e $5 \%$ pelo teste $\mathrm{F}$, não apresentando diferença estatística para as variáveis diâmetro e comprimento do caule 
Tabela 3. Resumo da análise de variância do número de folhas (NF), altura da planta (AP), diâmetro do caule (DC), comprimento radicular (CR), volume radicular (VR), massa fresca da parte aérea (MFPA), massa fresca do sistema radicular (MFSR), massa seca da parte aérea (MSPA) e massa seca do sistema radicular (MSSR) de mudas de ipê roxo sob crescentes proporções de caule decomposto de babaçu.

\begin{tabular}{cccccccccc}
\hline $\begin{array}{c}\text { Fonte de } \\
\text { Variação }\end{array}$ & NF & $\begin{array}{c}\text { AP } \\
-\mathrm{cm}-\end{array}$ & $\begin{array}{c}\mathrm{DC} \\
-\mathrm{mm}-\end{array}$ & $\begin{array}{c}\mathrm{CR}- \\
-\mathrm{cm}-\end{array}$ & $\begin{array}{c}\text { VR } \\
-\mathrm{cm}^{3}-\end{array}$ & $\begin{array}{c}\text { MFPA } \\
-\mathrm{g}-\end{array}$ & $\begin{array}{c}\text { MFSR } \\
-\mathrm{g}-\end{array}$ & $\begin{array}{c}\text { MSPA } \\
-\mathrm{g}-\end{array}$ & $\begin{array}{c}\text { MSSR } \\
-\mathrm{g}-\end{array}$ \\
\hline Resíduo & 1,3472 & 3,9744 & 0,6400 & 29,0668 & 0,0054 & 0,0001 & 0 & 0,0016 & 0,0003 \\
\hline T1 & $10,00 \mathrm{~b}$ & $8,25 \mathrm{~b}$ & $3,03 \mathrm{a}$ & $18,73 \mathrm{a}$ & $0,63 \mathrm{~d}$ & $1,24 \mathrm{a}$ & $0,09 \mathrm{e}$ & $1,67 \mathrm{~d}$ & $0,51 \mathrm{~d}$ \\
$\mathrm{~T} 2$ & $11,00 \mathrm{ab}$ & $8,28 \mathrm{~b}$ & $3,28 \mathrm{a}$ & $14,25 \mathrm{a}$ & $0,73 \mathrm{~d}$ & $0,37 \mathrm{f}$ & $0,09 \mathrm{e}$ & $2,04 \mathrm{c}$ & $0,53 \mathrm{~d}$ \\
T3 & $11,75 \mathrm{ab}$ & $9,13 \mathrm{ab}$ & $3,30 \mathrm{a}$ & $15,88 \mathrm{a}$ & $1,08 \mathrm{c}$ & $0,45 \mathrm{~d}$ & $0,14 \mathrm{c}$ & $2,06 \mathrm{c}$ & $0,93 \mathrm{c}$ \\
T4 & $12,75 \mathrm{a}$ & $13,40 \mathrm{a}$ & $4,63 \mathrm{a}$ & $23,30 \mathrm{a}$ & $2,43 \mathrm{a}$ & $1,12 \mathrm{~b}$ & $0,31 \mathrm{a}$ & $5,20 \mathrm{a}$ & $2,05 \mathrm{a}$ \\
T5 & $12,00 \mathrm{ab}$ & $8,98 \mathrm{ab}$ & $3,85 \mathrm{a}$ & $20,43 \mathrm{a}$ & $1,40 \mathrm{~b}$ & $0,74 \mathrm{c}$ & $0,20 \mathrm{~b}$ & $3,38 \mathrm{~b}$ & $1,27 \mathrm{~b}$ \\
T6 & $11,25 \mathrm{ab}$ & $9,48 \mathrm{ab}$ & $3,13 \mathrm{a}$ & $23,45 \mathrm{a}$ & $1,43 \mathrm{~b}$ & $0,40 \mathrm{e}$ & $0,13 \mathrm{~d}$ & $2,00 \mathrm{c}$ & $0,90 \mathrm{c}$ \\
\hline DMS & 2,60 & 4,48 & 1,79 & 12,11 & 0,16 & 0,01 & 0,01 & 0,09 & 0,03 \\
\hline C.V. & 10,13 & 20,80 & 22,64 & 27,88 & 5,75 & 1,20 & 1,58 & 1,49 & 1,55 \\
\hline
\end{tabular}

$\mathrm{T} 1=100 \%$ de Solo; T2= 20\% de CDB + 80\% de Solo; T3=40\% de CDB + 60\% de Solo; T4= 60\% de CDB + 40\% de Solo; T5= $80 \%$ de CDB + 20\% de Solo; T6= $100 \%$ de CDB; DMS: diferença mínima significativa; CV: coeficiente de variação; **: Significativo ao nível de $1 \%$ de probabilidade, pelo teste F; *: Significativo ao nível de $5 \%$ de probabilidade, pelo teste F; ns: não significativo.

O substrato formulado por $60 \%$ de CDB $+40 \%$ solo proporcionou um melhor desempenho para a variável número de folhas. Compreende-se que devido a presença do nitrogênio que é um nutriente importante. Assim é possível afirmar que, o caule decomposto de babaçu contribuiu como fonte de nitrogênio para o substrato e a medida que são aumentadas as proporções de CDB a quantidade de folhas se desenvove melhor. Diferente do que foi relatado por Oliveira Neto et al. (2018b) em trabalhos realizados com pepino (Cucumis sativus L.) não houve diferença estatística na utilização do substrato para esta variável.

As crescentes proporções de caule decomposto de babaçu proporcionaram um maior crescimento das mudas de Ipê-roxo (Tabebuia impetiginosa), onde o tratamento com $60 \%$ de CDB apresentou a melhor média para essa variável, sendo que todos os tratamentos com CDB apresentaram resultados superiores à média apresentada pela testemunha. Isso se dá pela espécie ser pouco exigente em fertilidade do solo durante o seu crescimento. Goulart et al. (2017) em trabalho realizado com Ipêamarelo (Tabebuia serratifolia) sobre fertilização nitrogenada, a presença do enxofre na fonte de $\mathrm{N}$ sulfato de amônio não influencia no crescimento das mudas de ipê-amarelo, pois já foi verificado que em espécies nativas como jacarandá-da-Bahia e canafístula esse nutriente é pouco requerido na fase de formação das mudas.

Quanto ao diâmetro do caule (tabela 3), não foi averiguado diferença entre os tratamentos utilizados, no entanto, o maior diâmetro foi observado no T4, com $60 \%$ de CDB $+40 \%$ de Solo, alcançando valor médio de 4,63 $\mathrm{mm}$.

Segundo Szareski1 et al. (2015), a avaliação do diâmetro do colo é de fundamental importância na avaliação do potencial das mudas para sobrevivência e crescimento após o plantio da espécie. Assim, as mudas devem apresentar maior diâmetro do colo, para potencializar o equilíbrio do crescimento da parte aérea. No entanto, a definição de um valor de diâmetro do colo depende de diversos fatores como espécie, local e das técnicas de produção.

Souza et al. (2013), dizem que o comprimento da parte aérea, combinado com o diâmetro do colo, constitui um dos mais importantes caracteres morfológicos para se estimar o crescimento das mudas após o plantio definitivo no campo. Freitas et al. (2013), dizem ainda que o diâmetro do caule é um bom indicador da qualidade da muda para a sobrevivência e crescimento após o transplantio para o local definitivo.

Para o comprimento radicular não houve diferença estatística entre os tratamentos, resultado este pode ser justificado pelo substrato a base de caule decomposto de babaçu não apresentar níveis satisfatórios do nutriente fósforo, que é essencial para o desenvolvimento radicular. Pois este nutriente estimula o crescimento das raízes, garantindo um maior desenvolvimento e vigorosidade da planta quando transplantada no campo (SILVA et al., 2017). Outro fator que pode interferir no desenvolvimento radicular é a aeração. Malavolta, 
Romero (1975) explicam que a ausência da quantidade adequada de aeração no substrato torna as raízes mais grossas, curtas e escurecidas, apresentando pequena quantidade de pelos absorventes, comprometendo o desenvolvimento da parte aérea, o que não ocorreu no presente trabalho.

O tratamento composto de $60 \% \mathrm{CDB}+40 \%$ solo (T4) proporcionou maior volume radicular, apresentando média de $2,43 \mathrm{~cm}^{3}$, este resultado pode estar relacionado aos substratos formulados com caule decomposto de babaçu apresentarem características físicas e químicas satisfatórias para o desenvolvimento de mudas. De acordo com Andrade et al. (2017), o sistema radicular só se desenvolve satisfatoriamente quando o substrato combina boa aeração com alta capacidade de retenção de água, boa drenagem e ausência de contaminantes, o que em consequência gera um bom desenvolvimento da parte aérea.

A massa fresca da parte aérea (MFPA) apresentou seu melhor resultado quando submetido ao tratamento de $100 \%$ de Solo, este resultado pode está relacionado a cultura do Ipê roxo (Tabebuia impetiginosa) ser pouco exigente em fertilidade do solo e a boa condição de aeração que o solo apresenta. Albano et al. (2014) trabalhando com substrato alternativo para produção de mudas de mamoeiro formosa (Carica Papaya L.) utilizando caule decomposto de buriti verificaram que quanto menor a concentração deste, no substrato, menor foi a capacidade de retenção de água, mostrando que já que areia é um material poroso irá facilitar a aeração.

Analisando-se a Tabela 3, verifica-se que o T4, composto de $60 \%$ de CDB $+40 \%$ de Solo proporcionou os maiores valores de massa fresca do sistema radicular, massa seca da parte aérea e massa seca do sistema radicular diferindo estatisticamente dos demais tratamentos.

Quanto a massa seca da parte aérea (MSPA), quanto maior a massa, maior será a capacidade fotossintética e maior o vigor das plantas, e diferentemente do que foi relatado por Andrade et al. (2017) em experimento com mudas de melancia (Citrullus lanatus), os maiores valores foram encontrados nos substratos com maiores quantidades de CDB, enquanto que para o ipê roxo (Tabebuia impetiginosa) o substrato composto de $60 \%$ de CDB foi o que apresentou os maiores valores.

No que se refere a massa seca do sistema radicular (MSSR), para que haja um bom desenvolvimento é necessário que o substrato tenha uma boa combinação da aeração com alta capacidade de retenção de água. Delarmelina et al. (2014) citam que raízes de plantas jovens necessitam do oxigênio para o processo respiratório, que advém do próprio substrato. Com isso, infere-se que há a necessidade de os substratos apresentarem boa aeração para maior crescimento das raízes.

No que diz respeito à massa fresca do sistema radicular (MFSR), o T4 apresentou diferença significativa entre os tratamentos com 0,31g. Devido à composição dos tratamentos como fonte orgânica, refletindo em maiores taxas de umidade, fornecendo nutrientes e condições adequadas ao desenvolvimento e crescimento das raízes. Fernandes et al. (2015) em experimento com maracujazeiro amarelo (Passiflora edulis L) verificaram que a matéria fresca foi alterada significativamente pelo conteúdo de umidade no substrato.

\section{CONCLUSÃO}

O substrato com $60 \%$ de caule decomposto de babaçu (Attalea speciosa) apresenta melhores resultados na produção de mudas de ipê-roxo. Sendo uma alternativa para os produtores, levando em consideração além de seus efeitos positivos sobre as mudas, também sua fácil aquisição.

\section{REFERÊNCIAS}

ALBANO, G. F.; MARQUES, A. S.; CAVALCANTE, I. H. L. Substrato alternativo para produção de mudas de mamoeiro formosa ( $c v$. Caliman). Científica, Jaboticabal, v. 42, n. 4, p. 388-395, 2014.

ALVES, F. J. B.; FREIRE, A. L. O. Crescimento inicial e qualidade de mudas de ipê-roxo (Handroanthus impetiginosus (Mart. ex DC) Mattos) produzidas em diferentes substratos. Revista Agropecuária Científica no Semiárido, Patos, v. 13, n. 3, p. 195-202, 2017.

ANDRADE, H. A. F.; COSTA, N. A.; CORDEIRO, K. V.; OLIVEIRA NETO, E. D.; ALBANO, F. G.; SILVAMATOS, R. R. S. Caule decomposto de babaçu (Attlea speciosa Mart.) como substrato para produção de mudas de melancieira. Cultura Agronômica, Ilha Solteira, v. 26, n. 3, p. 406-416, 2017.

BASSO, C. J. Épocas de aplicação de nitrogênio para o milho cultivado em sucessão a plantas de cobertura de solo, no sistema plantio direto. 1999. 91 f. Tese (Mestrado em Agronomia) - Universidade Federal de Santa Maria, Santa Maria.

BORBA FILHO, A. B.; PEREZ, S. C. J. G. A. Armazenamento de sementes de ipê-branco e ipê-roxo em diferentes embalagens e ambientes. Revista Brasileira de Sementes, Londrina, v. 31, n. 1, p. 259-269, 2009.

CRUZ, A. C.; LIMA, J. S.; ANDRADE, H. A. F.; OLIVEIRA, A. R. F.; LEITE, M. R. L.; SILVA, L. R.; SILVA, T. F.; GONDIM, M. M. S.; MACHADO, N. A. F.; SILVA-MATOS, R. R. S. Stalk decomposed babassu for production of seedlings of Bougainvillea spectabilis 
Willd in different levels of indolebutyric acid. Asian academic research journal of multidisciplinary, v. 5, p. 98-109, 2018.

DELARMELINA, W. M.; CALDEIRA, M. V. W.; FARIA, J. C. T.; GONÇALVES, E. O.; ROCHA, R. L. F. Diferentes substratos para a produção de mudas de Sesbania virgata. Floresta e Ambiente, Rio de Janeiro, v. 21, n. 2, p. 224-233, 2014.

FERNANDES, D. A.; ARAUJO, M. M. V.; CAMILI, E. C. Crescimento de plântulas de maracujazeiro-amarelo sob diferentes lâminas de irrigação e uso de hidrogel Revista de Agricultura, Piracicaba, v. 90, n. 3, p. 229236, 2015 .

FREITAS, G. A.; SILVA, R. R.; BARROS, H. B.; MELlO, A. V.; ABRAHÃO, W. A. P. Produção de mudas de alface em função de diferentes combinações de substratos. Revista Ciência Agronômica, Fortaleza, v. 44, n. 1, p. 159-166, 2013.

GOULART, L. M. L.; PAIVA, H. N.; LEITE, H. G.; XAVIER, A.; DUARTE, M. L. Produção de mudas de Ipê-amarelo (Tabebuia serratifolia) em resposta a fertilização nitrogenada. Floresta e Ambiente, Rio de Janeiro, v. 24, p. 137-315, 2017.

MALAVOLTA, E.; ROMERO, J. P. Manual de adubação. 2 ed. São Paulo: ANDA, 1975. 346 p.

OLIVEIRA NETO, E. D.; ANDRADE, H. A. F.; OLIVEIRA, A. R. F.; MORAES, L. F.; SANTOS, L. R.; PONTES, S. F.; COSTA, N. A.; LOPES. P. R. C.; OLIVEIRA, I. V. M.; SILVA-MATOS, R. R. S Vegetative propagation of pomegranate 'Wonderful' in substrates of decomposed babassu stem. Asian academic research journal of multidisciplinary, v. 5, p. 167-179, 2018.

OLIVEIRA NETO, E. D.; ROCHA, B. R. S.; CORDEIRO, K. V.; COSTA, N. A.; ALBANO, F. G.; SILVA-MATOS, R. R. S. Mudas de Pepineiro Utilizando Como Substrato Caule Decomposto de Babaçu. In: ALFARO, A. T. S.; TROJAN, D. G. T. (Org.). Agronomia: Elo da Cadeia Produtiva - Vol. 2. 1ed. Ponta Grossa - PR: Atena Editora, 2018, v. 2, p. 105-116.

OLIVEIRA, T. P. F.; BARROSO, D. G.; LAMÔNICA, K. R.; CARVALHO, V. S.; OLIVEIRA, M. A. Efeito do ácido indol-3-butírico (AIB) no enraizamento de miniestacas de ipê-roxo (Handroanthus heptaphyllus Mattos). Ciência Florestal, Santa Maria, v. 25, n. 4, p. 1043-1051, 2015.

OLIVEIRA, A. R. F.; PONTES, S. F.; MORAIS, S. F.; ANDRADE, H. A. F.; MENDES, F. C.; MACHADO, N. A. F.; SILVA-MATOS, R. R. S. Caracterização de Substratos Formulados a Partir de Caule Decomposto de Babaçu. In: ALFARO, A. T. S.; TROJAN, D. G. T. (Org.). Agronomia: Elo da Cadeia Produtiva. 1ed. Ponta Grossa - PR: Atena Editora, 2018, v. 1, p. 119-126.
PASSOS, M. L. V.; ZAMBRZYCKI, G. C.; PEREIRA, R. S. Balanço hídrico e classificação climática para uma determinada região de Chapadinha - MA. Revista Brasileira de Agricultura Irrigada, Fortaleza, v. 10, n. 4, p. 758-766, 2016.

SILVA, F. de A. S. E.; AZEVEDO, C. A. V. de. The Assistat Software Version 7.7 and its use in the analysis of experimental data. Afr. Journal Agricultural Research, v. 11, n. 39, p. 3733-3740, 2016. Disponível em: DOI: 10.5897/AJAR2016.11522.

SILVA, M. R. R.; IGNACIO, L. A. P.; SILVA, G. A. Desenvolvimento de mudas de maracujá amarelo em função de diferentes doses fósforo reativo. Revista de Agronegócio, Jales, v. 6, n. 1, p. 41-50, 2017.

SOUZA, E. G. F.; BARROS JÚNIOR, A. P.; SILVEIRA, L. M.; SANTOS, M. G.; SILVA, E. F. Emergência e desenvolvimento de mudas de tomate IPA 6 em substratos, contendo esterco ovino. Revista Ceres, Viçosa, v. 60, n. 6, p. 902-907, 2013.

SZARESKI1, J. V.; SOUZA, V. Q.; NARDINO, M.; FERRARI, M.; MARTINI, R. T. Influência de diferentes substratos na produção de Peltophorum dubium. Enciclopédia Biosfera, Goiânia, v. 11, n. 22, p. 2015, 2015. 